\title{
"humanidades
}

Revista Humanidades

ISSN: 2215-3934

humanidades@ucr.ac.cr

Universidad de Costa Rica

Costa Rica

\section{Las olas del movimiento LGBTIQ+. Una propuesta desde la historiografía}

\author{
Vázquez Parra, Dr. José Carlos \\ Las olas del movimiento LGBTIQ+. Una propuesta desde la historiografía \\ Revista Humanidades, vol. 11, núm. 2, 2021 \\ Universidad de Costa Rica, Costa Rica \\ Disponible en: https://www.redalyc. org/articulo. $0 a ? \mathrm{id}=498066660003$ \\ DOl: https://doi.org/10.15517/h.v11i2.47311
}

\section{(c) (1) $\Theta \Theta$}

Esta obra está bajo una Licencia Creative Commons Atribución-NoComercial-SinDerivar 3.0 Internacional. 
Desde los estudios étnicos, culturales, de género y ambientales

\section{Las olas del movimiento LGBTIQ+. Una propuesta desde la historiografía}

The Waves of the LGBTIQ+ Movement. A Proposal from Historiography

Dr. José Carlos Vázquez Parra

Escuela de Humanidades y Educación, Tecnológico de

DOI: https://doi.org/10.15517/h.v11i2.47311

Monterrey, Guadalajara, México

Redalyc: https://www.redalyc.org/articulo.oa?

jcvazquezp@tec.mx

(iD) https://orcid.org/0000-0001-9197-7826

$\mathrm{id}=498066660003$

Recepción: 29 Septiembre 2020

Aprobación: 18 Febrero 2021

\section{Resumen:}

La historia de la homosexualidad y la historia del movimiento homosexual son dos cuestiones parecidas, pero, a su vez, muy diferentes. Mientras que la primera hace un abordaje sobre las prácticas y el desarrollo de la homosexualidad en la historia de la humanidad, la segunda se enfoca en la lucha por el reconocimiento y la igualdad de derechos de todas las personas que pertenecen a los grupos de la diversidad sexual. Así, el propósito del presente artículo es realizar una aproximación al movimiento homosexual en Occidente, al plantear la posibilidad de clasificar tres etapas a partir de los objetivos propios que perseguía el activismo y sus actores en dichos momentos. Para llegar a esto, se utiliza una metodología historiográfica. Como conclusión, se consigue identificar que, aunque históricamente se tenía una meta común, la intencionalidad de cada temporalidad y territorialidad fue distinta y, a su vez, necesaria para avanzar en las etapas posteriores del movimiento.

Palabras ClaVE: grupo sexual minoritario, historia, sexualidad, movimientos de liberación.

\section{Abstract:}

The history of homosexuality and the history of the homosexual movement are two similar but very different issues. While the former deals with the practices and development of homosexuality in the history of humanity, the latter focuses on the struggle for recognition and equal rights for all people belonging to groups of sexual diversity. Thus, the purpose of the present paper is to approach the homosexual movement in the West, proposing the possibility of classifying three stages on the basis of the objectives pursued by activism and its actors at those times. To achieve this, a historiographic methodology is used. In conclusion, it is possible to identify that, although historically there was a common objective, the intentionality of each temporality and territoriality was different and at the same time necessary to be able to advance in the subsequent stages of the movement.

KEYWORDS: sexual minorities, history, sexuality, liberation movements.

\section{INTRODUCCIÓN}

Las olas o etapas de un movimiento social son, al igual que las olas del mar, irrepetibles, pero con patrones semejantes. Los movimientos sociales son únicos debido al contexto histórico del que brotan, pero tienen en común el hecho de haber surgido a partir de la intención de lucha por mejores condiciones para las personas. Siguiendo con esta idea, las olas de un movimiento social son un constante ir y venir de legítimas demandas económicas, políticas y sociales que buscan, poco a poco, avanzar en la conquista de derechos. En ese vaivén, las olas pueden llegar a retroceder, pero es únicamente con el objetivo de expandirse con mayor intensidad.

Cuando se habla de olas, usualmente, se hace referencia a las llamadas olas del feminismo. Con relación a esto, el término comenzó a emplearse en 1968, después de que Martha Weinman aludiera a la segunda ola del feminismo en el New York Times (Nicholson, 2010). A partir de allí, se acogió la metáfora del mar para representar las movilizaciones sociales y sus luchas que, como el mar, poseían constancia, envolvimiento y ferocidad dentro del ámbito social y político. Como señala Weinman (citado por Suárez, 2019), las olas como representación simbólica permiten comprender aquellos movimientos sociales que implican una lucha 
continua; aunque en algunos momentos estos fueron más apacibles, en otros presentaban picos de intensidad. No obstante, no se puede asumir que el movimiento feminista sea el único que ha tenido estas características, ya que al igual que la lucha de las mujeres por la igualdad, existen otros grupos que se han involucrado en la lucha por los derechos igualitarios.

De esta manera, en este artículo se plantea la posibilidad de una clasificación del movimiento LGBTIQ+ (acrónimo que incluye a la comunidad lésbica, gay, bisexual, trans, intersexual, queer y el resto de diversidades sexuales y de género representadas con el signo “+”) en tres olas o etapas del activismo en Occidente. Además, se propone la necesidad de señalar momentos concretos que, aunque pertenecían a la misma lucha, se caracterizaron por su intensidad, así como por la participación de diversos tipos de agentes (económicos, sociales, políticos, de salud, etc.). La presente clasificación no se utiliza para señalar características propias o únicas de cada etapa, sino más bien, como un elemento que posibilita una clarificación de estos momentos históricos y sus implicaciones.

La metodología aplicada en este abordaje es la historiográfica, ya que el movimiento LGBTIQ+ se produce como resultado de un problema social asentado en un momento histórico, el cual no siempre se adecúa a otros parámetros materiales o inmateriales diferentes al statu quo. De esta manera, la historia permite analizar los fenómenos sociales desde una perspectiva que los contextualiza, en este caso, el desarrollo de los movimientos de activismo.

La elección de esta metodología quizá limitaría el abordaje de todas las características que se podrían incluir como parte de esta clasificación, por ejemplo, los procesos sociales, políticos y culturales de carácter material e inmaterial. Sin embargo, este artículo es un primer abordaje que posibilita nuevas investigaciones, las cuales podrían desarrollar las implicaciones de esta propuesta de clasificación.

Adicionalmente, aunque se puede señalar la historia y el desarrollo propio de otras regiones como Oriente, África y Medio Oriente, el presente artículo aborda únicamente el activismo que se ha generado en Occidente.

\section{ANTECEDENTES}

La homosexualidad no puede ser situada en un único periodo histórico, ya que se puede considerar como una situación que ha acompañado al desarrollo mismo de la humanidad. Por ende, la intención de hablar de sus antecedentes implica realizar un amplio abordaje del pasado, sin importar la cultura, la región o el continente (Bidstrup, 2001).

Desde el inicio del registro de la historia Occidental es posible ubicar el tema de la homosexualidad. Por ejemplo, en Mesopotamia se pueden encontrar descripciones de la homosexualidad masculina, la cual era considerada como parte de los rituales religiosos llevados a cabo por sacerdotes especiales llamados assinus (Valdés, 1981). Por su parte, en Babilonia, hace más de 4000 años, ya se documentaba la homosexualidad como algo cotidiano entre las personas, cuyas relaciones homoeróticas eran parte del imaginario de la región. Esto se puede apreciar en el famoso relato épico de Gilgamesh o en el culto a Ishtar en el que el travestismo y la prostitución masculina eran manifestaciones culturales usuales y sagradas. Sin embargo, en otras partes de la región se trataba diferente, por ejemplo, los asirios tenían fuertes leyes en contra de la homosexualidad masculina, la cual se condenaba con cincuenta golpes con bastón, trabajo comunitario al rey o la castración (Bidstrup, 2001).

En esa misma línea, en Grecia, la homosexualidad era considerada normal, tanto con fines formativos como religiosos. Había claros ejemplos entre las historias de los soldados tebanos o la relación de Alejandro Magno y Hefestión. Poetas como Horacio, Virgilio y Ovidio enaltecieron el homoerotismo griego; estos escritores pusieron especial atención a las prácticas masculinas, al considerar que las relaciones entre hombres resultaban ser mejores y más placenteras por darse entre seres más perfectos que las mujeres, quienes eran consideradas inferiores (Aries, 1987). 
En Roma, aunque la homosexualidad no era bien vista siguió siendo una práctica usual entre las personas. Hubo múltiples señalamientos acerca de los amantes masculinos de sus emperadores, como fueron los casos de Julio César, Marco Antonio, Octavio y Nerón (Rayor, 2003). En el siglo I, la legislación romana consideraba la posibilidad del matrimonio entre hombres, aunque es importante señalar que, en este caso, el vínculo tenía más un trasfondo contractual que amoroso. Aun así, son ejemplos de que la homosexualidad no resultaba ser ni perseguida ni penada (Bidstrup, 2001).

Ahora bien, mientras esto pasaba en Occidente, en Oriente se desarrollaba una línea histórica semejante. En la India, las leyes de Manu del siglo III a. C. contemplaban las prácticas homosexuales como actos aceptados, los cuales ya eran mencionados desde el siglo IV a. C. en el Kamasutra (Vanita, 2002). En China, según investigaciones de Pan Guangdan, era usual que los emperadores tuvieran uno o varios amantes masculinos; por esto, la homosexualidad fue una práctica tan usual que no es raro encontrar su registro en el arte de la región y en la literatura clásica. Por su parte, en Japón, la homosexualidad era cotidiana tanto entre los monjes budistas como entre la casta de los samuráis (Dynes y Donaldson, 1992a).

Tras el desarrollo del cristianismo, la aceptación social de la homosexualidad comenzó a cambiar drásticamente durante la Edad Media, por lo que impactó rápidamente el imaginario de Occidente. Tanto Constantino como Justiniano implementaron la persecución y el castigo de la homosexualidad, lo cual incluía penas corporales e incluso la muerte (Rayor, 2003). Esta visión se extendió por los terrenos en donde el cristianismo se iba asentando. Así, se señaló la sodomía no solo como un pecado grave, sino también como un delito que ofendía a Dios y que atentaba contra el orden social (Tamagne, 2006). Desde el siglo V, las torturas y penas capitales relacionadas con el delito de homosexualidad eran cada vez más habituales, lo cual atendía directamente al santo oficio de la Iglesia católica (Bullough, 2019). Así, la percepción de la homosexualidad a partir de la Edad Media se constituyó sobre las prohibiciones, lo antinatural y lo nefasto. Todo ello asentó gran parte del ideario cultural que aún sigue presente en los países con influencia cristiana.

Este abordaje histórico, aunque es parte de los antecedentes de la homosexualidad, no puede considerarse como parte de sus etapas porque, a pesar de la presencia de prácticas homosexuales, no se cuenta con registros que señalen algún tipo de lucha por el reconocimiento o el respeto de derechos, aspecto considerado como criterio de exclusión en este estudio. Hasta este punto histórico, la homosexualidad era parte de la cotidianidad de las personas; una práctica y no una característica que permitiera identificar a un grupo poblacional o a su lucha política y social.

\section{Primera ola: Del nacimiento del término a La humanización de la HOMOSEXUALIDAD}

En 1836, se publica Eros de Heinrich Hössli que puede considerarse la primera obra escrita que se refería directamente al tema de la homosexualidad. En sus dos volúmenes, Hössli desarrollaba la noción de homosexualidad a partir de una reflexión del homoerotismo griego y la visión cristiana de la Edad Media. En sus páginas, se buscaba demostrar históricamente la presencia del amor masculino en la literatura persa, griega y romana, así como también explicar la irracionalidad de los diferentes prejuicios que se dirigían hacia estas prácticas. Aunque su obra tuvo muy poca recepción, consiguió motivar a quien se consideraría el primer activista LGBTIQ+ de Occidente, el abogado alemán Karl Ulrichs (Dynes y Donaldson, 1992b).

En 1864, Karl Ulrichs publica Estudios sobre el enigma del amor masculino, texto en el que abogaba por la existencia de un tercer sexo, el cual se configuraba con un cuerpo masculino, pero con una psique femenina. Con ello, se argumentaba que la homosexualidad era una cuestión natural y biológica que se denominaba uranismo, concepto que se refería al simbolismo de Urano, un ser hermafrodita narrado en El Banquete, de Platón (Hekma, 1989). Al igual que el texto de Hössli, este libro de Ulrichs tampoco fue bien acogido por la sociedad europea. 
A pesar de este fracaso, Karl Ulrichs pudo llamar la atención de otros académicos interesados en el tema, como es el caso de Károly Maria Kertbeny, quien se unió a Ulrichs para luchar por la despenalización de la homosexualidad, la cual había sido tipificada en Alemania en 1872 (Tamagne, 2006). De esta forma, de 1870 a 1940, se gestó en Europa una primera manifestación de la lucha por parte de un grupo de pensadores y académicos, en su mayoría alemanes, en contra de las normas que prohibían y castigaban la homosexualidad en diferentes países (Aries, 1987).

A partir del proceso judicial que se entabló en 1897 contra Oscar Wilde por cargos de sodomía y grave indecencia en Inglaterra, Magnus Hirschfeld, Max Spohr, Eduard Oberg y Franz Joseph von Bülow fundaron el Comité Científico Humanitario, considerado la primera organización homosexual, cuyo objetivo era establecer el determinismo biológico de la homosexualidad. Este comité generó varios esfuerzos para dar a conocer su postura al gobierno alemán, incluso llegó a reunir miles de firmas de pensadores, académicos y agentes políticos que se manifestaban en contra de la legislación que penalizaba la homosexualidad (Bullough, 2019).

En 1903, Adolf Brand funda la Comunidad de los Propios, la cual, a diferencia del Comité Científico Humanitario, se enfocaba únicamente en las relaciones masculinas y rechazaba la homosexualidad femenina, ya que consideraba la inferioridad de las mujeres (Halperin, 1990). Para Brand, la homosexualidad no era una cuestión biológica, sino más bien cultural. Él tomaba en consideración que la superioridad de los hombres los llevaba a relacionarse entre ellos como una forma de desarrollar un mejor ser humano. Así, planteaba que los jóvenes debían ser formados por otros hombres para evitar ser afectados por la visión imperfecta de las mujeres (Tamagne, 2006). Cabe señalar que el movimiento lésbico tuvo poca presencia en esta primera ola, ya que la situación general de las mujeres era bastante precaria en cuanto a sus derechos y los pocos esfuerzos llevados a cabo ocurrieron más dentro de los movimientos feministas (Valdés, 1981).

De esta manera, ambos grupos, el Comité Científico Humanitario y la Comunidad de los Propios fueron desarrollando sus visiones hasta el inicio de la I Guerra Mundial, periodo en el que hubo poco avance con relación a estos temas. Sería hasta 1919 que Magnus Hirschfeld crearía el Instituto para la Ciencia Sexual, organización que buscaba promover el estudio científico de la vida sexual e indagar sobre cómo llegar a una mejor y más clara explicación de la homosexualidad y del travestismo. A partir de su labor en este instituto, Hirschfeld fundaría, en 1928, la Liga Mundial para la Reforma Sexual, la cual emprendía el objetivo de mejorar los derechos homosexuales en toda Europa. A la par de esta nueva organización, se reconocen los esfuerzos de otros grupos como la Liga de Amigos de Berlín, la Liga de la Amistad de Alemania y la Comisión de Acción, grupos que durante la década de los veinte buscaron reunir mayores esfuerzos para la aceptación y el reconocimiento de la homosexualidad, así como su despenalización (Dynes y Donaldson, 1992b).

A pesar del avance en esta primera etapa de activismo, ya para 1930, con la supremacía del Partido Nacionalsocialista Obrero Alemán como segunda mayor fuerza política, el ambiente llegó a ser muy peligroso para la manifestación pública, hecho que se agravó con la llegada de Hitler al poder en 1933. Durante ese mismo año, se ordenó el cierre, la disolución y la cancelación de todas las publicaciones, así como de las organizaciones relacionadas con homosexuales, y destruyeron cualquier registro $\mathrm{u}$ obra que fuera contraria al espíritu nacionalista alemán (Whisnant, 2012).

De esta forma, se puede considerar que la II Guerra Mundial fue un hito, un espacio en blanco para los movimientos y el activismo homosexual en Occidente. Este hecho histórico retardó la lucha que se desarrollaba durante esta primera ola. Aun así, esta etapa se caracterizó por el auge de la psicología y por una visión mucho más humana de la persona homosexual. Desde esta perspectiva, la persona se transformaba de pecadora a alguien con una situación psicológica distinta o, según Freud, un desarrollo psicosexual incompleto (Hekma, 1989).

Aunque el eje central del activismo se gestó en Alemania, es posible encontrar manifestaciones de esta primera ola en otros países de Europa, por ejemplo, en Inglaterra, donde se puede señalar la fundación de la Orden de Queronea en 1897, así como la creación de la Sociedad Británica para el estudio de la psicología 
sexual en 1914 (Levy, 2020). Asimismo, en Italia, la Sociedad Italiana para el estudio de la sexualidad publicó en 1921 la revista Rassegna di studi sessuali. De igual manera, en España, en 1932 se fundó la Liga Española por la Reforma Sexual. Fuera de Europa, en Estados Unidos, se funda la primera organización relacionada con la homosexualidad en 1924: la Sociedad por los Derechos Humanos. Esta agrupación publicó, a su vez, la primera revista con temática homosexual de dicho país: Amistad y Libertad (Ayoub y Paternotte, 2014).

\section{SEgunda OLA: La homofilia}

Después de la segunda guerra mundial, en la cual se calculó la muerte de entre 10000 y 15000 personas homosexuales en campos de concentración, el arduo trabajo de activismo realizado en Alemania se detuvo. La penalización de la homosexualidad siguió siendo una ley vigente en ambas Alemanias. Ser homosexual traía consigo un estigma legal que impidió el desarrollo de la causa como se venía dando durante la primera ola. Prácticamente la homosexualidad era ilegal en todos los países occidentales y, por si fuera poco, en 1952 la Asociación Psiquiátrica Americana (APA) clasificó la homosexualidad como un desorden mental. Esta realidad justificó la realización de experimentos que, bajo apelativos normalizadores, buscaban eliminar la homosexualidad a través de tratamientos médicos crueles, violentos y deshumanizantes como la terapia de choques eléctricos y la lobotomía (Bidstrup, 2001).

Aun así, la lucha por la igualdad de derechos siguió su rumbo, aunque ahora se plantearía de manera predominante, desde Europa Occidental y los Estados Unidos, con el llamado movimiento homófilo (Halperin, 1990).

La denominación de homófilo fue propuesta por Karl Güther Heimsoth, quien pretendía modificar el uso de la palabra homosexual con el fin de enfatizar el amor en lugar del sexo. Una de las características más marcadas de lo que sería esta segunda ola fue la tendencia a modificar los estereotipos preconcebidos que se tenían acerca de la homosexualidad, cuyo mayor énfasis se situaba en la relación y la amistad entre varones que en el homoerotismo, la promiscuidad, el sexo, la desviación y la enfermedad mental (Logan, 2013). Para conseguir este cambio, los activistas de la época buscaron que las personas homosexuales fueran aceptadas e incluidas como miembros respetables de la sociedad, a través de amplios programas de divulgación científica sobre la homosexualidad que tenían la intención de mostrarle a la sociedad que las diferencias entre homosexuales y heterosexuales era una cuestión menor y de carácter puramente privado. Para comprender mejor esta etapa, es importante distribuir su desarrollo en dos regiones: Europa y Estados Unidos. A pesar de que tenían objetivos semejantes, cada región subrayó características concretas del movimiento.

Por su cercanía con Alemania, Suiza fue uno de los pocos lugares en donde continuaron las publicaciones que ya se venían dando en Alemania en la primera ola. Se divulgaban a través de la revista El Círculo, la única publicación para homosexuales que siguió editándose durante la guerra. Esta revista buscaba ser una fuente de información confiable para la comunidad homosexual y, aunque la mayor parte de su tiraje era para consumo nacional, era posible conseguir la revista en algunos otros países europeos (Logan, 2013). A la par de esta revista, su impulsor, Karl Meier, organizaba reuniones con los lectores, con el fin de socializar el estilo de vida homófilo y abrir espacios para la expresión de la causa. En 1942, el código penal suizo legalizó las relaciones homosexuales entre adultos de más de veinte años, suceso que marcó un nuevo logro para el activismo de la región en tiempos de posguerra (Ayoub y Paternotte, 2014).

Una historia semejante se dio en Países Bajos, donde la revista Amistad y el Centro de Cultura y Diversión se plantearon como los primeros intentos por retomar el activismo después de la guerra. En este centro, no solo se promovía el estilo de vida homófilo, sino que también se realizaban reuniones en las que acudían hombres de todo el mundo interesados en el tema, centrándose en la educación sobre la homosexualidad a partir de conversaciones con intelectuales, líderes políticos e incluso personajes religiosos. De esta forma, el impacto generado fue tal que no tardaron en replicarse otros espacios como El Eslabón y el Argos. Estos 
espacios promovieron un cambio de actitud en la sociedad de la época y abrió un diálogo constante entre homosexuales y heterosexuales (Tamagne, 2006).

De igual forma, los países escandinavos (Suecia, Noruega, Dinamarca y Finlandia) tuvieron su propia lucha, inició con la fundación de la asociación Círculo en 1948, la cual hacía referencia a la revista suiza y buscaba unirse al movimiento homófilo existente en Europa. El éxito del grupo fue considerable pues a un año de su fundación ya contaba con más de doscientos miembros, los cuales llegaron a ser más de mil doscientos en 1951. El objetivo primordial de la organización era promover los vínculos entre las personas homosexuales, establecer alianzas que les permitieran desarrollarse en un ambiente amigable y de respeto y abolir la penalización de la homosexualidad en todos los países de la región (Dynes y Donaldson, 1992b). Cabe señalar que, a pesar de esta aparente aceptación, la persecución hacia los homosexuales en estos países del norte de Europa seguía siendo una realidad y el hecho de ser identificado o detenido en una práctica homosexual podía traer una pena de mínimo seis meses de prisión (Rydström y Mustola, 2007).

A pesar de lo anterior, los esfuerzos de la región siguieron dando resultados y en 1952 se fundó en Dinamarca la Organización Internacional Homosexual, la cual tenía como objetivo el promover la tolerancia, el entendimiento mutuo entre las personas y la igualdad de derechos. Para conseguir esto, se planteó la distribución de materiales impresos en diez diferentes grupos, constituidos en varias ciudades de Europa. Asimismo se organizaron encuentros internacionales (Rydström y Mustola, 2007).

De una forma no tan positiva, Alemania Occidental tuvo varios intentos de adoptar la lucha homófila. En 1950, se fundó el Instituto para el Estudio de la Sexualidad, el cual contaba con una sección llamada Comité Científico Humanitario, que hacía referencia al grupo de Hirschfeld, Spohr, Oberg y von Bülow. De igual forma, en 1951, se creó la Sociedad por los Derechos Humanos, cuyo objetivo era liberar a los homosexuales de la persecución (Whisnant, 2012). Sin embargo, todos los intentos homófilos se disolvieron en 1957, cuando se llevaron a cabo diferentes persecuciones judiciales en Fráncfort en contra de las conductas inmorales. Se calcula que entre 1945 y 1969 se condenaron a más de cincuenta mil hombres en Alemania Occidental, lo cual llegó a su fin hasta 1969 cuando se abolió la ley que tipificaba la homosexualidad.

De forma parecida a Alemania, en Francia, la realidad fue muy compleja, ya que existía una clara penalización de la homosexualidad en el código penal, dicha criminalización se mantuvo hasta 1982. Por ende, el movimiento homófilo se enfocó primordialmente en una postura de ocultamiento de la sexualidad, considerando que solo así se evitaban el rechazo y las reacciones agresivas de parte de la población heterosexual (Merrick y Sibalis, 2013).

En Reino Unido, la homosexualidad fue ilegal hasta 1967, lo cual provocó que hubiera fuertes persecuciones desde la década de los cincuenta. El principal esfuerzo de activismo homófilo fue la constitución de la Sociedad Homosexual de Reforma Legal, cuyo fin era eliminar las leyes contra la homosexualidad en todo Gran Bretaña. A pesar del rechazo gubernamental, este grupo promovió la educación de la población sobre este tema por medio de artículos en periódicos, folletos, reuniones y charlas en diferentes medios. En 1964, se fundó el Grupo por la Igualdad Homosexual, el cual fue considerado como la asociación homófila más relevante de la década de los setenta (Buckle, 2015).

A diferencia de Europa, el movimiento homófilo en los Estados Unidos estuvo marcado por una clara persecución gubernamental, así como por el apoyo y las alianzas con otros grupos minoritarios que buscaban igualmente el respeto de sus derechos y sus libertades. Durante la presidencia de McCarthy se estableció una postura de rechazo ante cualquier manifestación de grupos sociales, puesto que se consideraban infiltración de grupos comunistas que buscaban sembrar el desorden público (Baker, 2016). Para McCarthy, los grupos homosexuales formaban parte de una conspiración Soviética y, por ende, se argumentó que se llevara a cabo una campaña antihomosexual desde la cúpula superior de la Casa Blanca, que continuaría, incluso, con el presidente Eisenhower. En 1954, el FBI tenía un grupo especial que vigilaba a las organizaciones homosexuales, lo cual era considerado como un tema de seguridad nacional. Aun así, y a pesar de la presión y 
persecución gubernamental, el activismo homosexual estadounidense siguió ampliando su ámbito de lucha que buscaba una mayor visibilización (Wolf, 2009).

Con la llegada de Kennedy a la presidencia, algunas de estas actitudes se fueron mitigando. Así, en 1963, The New York Times publicó amplios artículos relacionados con temas de la homosexualidad. De igual manera, la industria cinematográfica de Hollywood cada vez más incluía el tema con mayor cotidianidad en sus producciones (Griffin, 2006). En Nueva York, comenzó a gestarse un grupo de intelectuales homosexuales entre los que se encontraba Lincoln Kirstein, Monroe Wheeler, Paul Cadmus y W.H. Auden, así como aliados a la causa, entre ellosTennessee Williams, Truman Capote y Gore Vidal. Esto hizo que la ciudad se convirtiera en uno de los principales centros de la vida homosexual, de hecho, incrementaron y se propagaron poco a poco las manifestaciones de barrios como Harlem, donde se encontraban múltiples locales para la comunidad (Geoghegan, 2019). Adicionalmente, otras ciudades comenzaron a desarrollar sus propios movimientos, como sucedió con Chicago, Los Ángeles y San Francisco. Esta última ciudad fue declarada la Capital gay de América en 1964 debido a su amplia actividad homosexual (Dynes y Donaldson, 1992b).

Ante esta efervescencia, el movimiento homófilo encontró un excelente espacio para establecer su lucha. Activistas como Jack Nichols y Franklin Kameny promovieron alianzas entre los grupos homosexuales y otras minorías y participaron activamente en los movimientos de derechos civiles de 1963 (Logan, 2013). Incluso el activista Bayard Rustin consejero de Martin Luther King, en los setenta, promovió la necesidad de alinear la lucha homosexual con la lucha racial que tenía lugar en ese momento (Wolf, 2009).

En cuanto a organizaciones civiles, en 1952, se fundó ONE Inc una organización que no solo editó la revista $O N E$, sino que también contaba con un instituto que desde 1957 ofrecía cursos sobre la historia de la homosexualidad. En 1954, se fundó la Mattachine Society que, a través de la Mattachine Review, divulgaba propaganda para el reconocimiento social de los homosexuales y que, en Washington, realizaba trabajo político para abolir la penalización de la homosexualidad. En 1955, en San Francisco, se funda Las Hijas de Bilitis, la cual se reconoce como la primera asociación lésbica de los Estados Unidos (Aries, 1987).

En 1964, se da la primera manifestación pública homosexual en los Estados Unidos, la cual se enfocaba, primordialmente, en manifestar un rechazo abierto hacia la discriminación de los homosexuales en el ejército. Esta primera manifestación se dio en Nueva York, pero se replicaría en Washington en 1965. De manera semejante, en 1967, cientos de personas se manifestaron en Los Ángeles en contra de las persecuciones policíacas y, en ese mismo año, la Universidad de Columbia reconoció la primera asociación estudiantil homosexual (D'Emilio, 2012).

De esta forma, se puede establecer que, aunque la II Guerra Mundial parecía una situación que sofocaría la flama de la lucha por la igualdad, solo enlenteció el proceso que, como se ha podido apreciar, se recuperó para los años sesenta. Bastaron un par de décadas para que la presencia de grupos homosexuales fuera cada vez más representativa, lo que promovió así la necesidad de visibilizar el estilo de vida homosexual y que dejó atrás el rechazo, el estigma, el delito y la pena. Aunque las situaciones de Europa y Estados Unidos resultaron ser diferentes, esta etapa demostró que el activismo seguía vivo a pesar de las posturas políticas, la presión religiosa y los imaginarios sociales.

Mientras la lucha y el activismo de la primera ola se enfocaron primordialmente en la socialización de conceptos y conocimientos sobre la homosexualidad, fuera de los parámetros meramente religiosos que la condenaban, en esta segunda ola el movimiento se perfiló hacia la visibilización de la vida de las personas homosexuales, quienes debían ser valorados de igual forma que los heterosexuales como ciudadanos y parte de sus sociedades. Así, aunque esta segunda ola tuvo que retroceder durante la II Guerra Mundial, no afectó el hecho de que avanzara considerablemente, lo cual marcó un precedente para lo que sería el denominado movimiento de liberación homosexual. 


\section{TERCERA OLA: EL MOVIMIENTO DE LIBERACIÓN GAY Y HOMOSEXUAL}

A finales de la década de los sesenta la realidad de la comunidad homosexual en Occidente se encontraba enmarcada por la incertidumbre, ya que, aunque había mayores libertades para poderse reunir y hablar sobre el tema, la presión gubernamental seguía siendo razón de constantes enfrentamientos entre los activistas y la policía. Si bien históricamente se puede hablar de un desarrollo en diferentes países y regiones del mundo, serían las movilizaciones en los Estados Unidos las que marcarían el inicio de la tercera ola.

Como se expuso, la década de los sesenta en los Estados Unidos se caracterizó por la gran cantidad de movimientos sociales que se encontraban activos, entre los cuales se pueden enunciar los movimientos afroamericanos, el movimiento hippie, las manifestaciones contra la guerra de Vietnam y la presión de grupos feministas (Weis, 2014). Lo anterior llevaba a que varios grupos poblacionales, entre ellos el homosexual, se percibieran como víctimas de represión gubernamental y, en consecuencia, sentían la necesidad de no quedarse callados. La hostilidad del Hobierno americano iba cambiando según el presidente en turno y la realidad de la población homosexual dependía, en gran medida, de la ciudad en la que vivieran (Jowett, 2017).

\subsection{El Disturbio}

Los barrios neoyorquinos de Greenwich Village y Harlem se convirtieron en espacios donde se concentró gran parte de la población homosexual durante la época de la posguerra. De esta forma, se fijó la pauta para una subcultura que se extendió durante varias décadas y que incluía pensadores, poetas y académicos de todo el país. Sin embargo, no era desconocido el hecho de que los homosexuales no podían trabajar para el Gobierno y que, si se era una persona abiertamente reconocida como homosexual, se le revocaban las licencias para laborar en profesiones como la medicina y el derecho. Además, diversos grupos ya comenzaban a manifestarse en San Francisco y Los Ángeles en contra de la represión policíaca; todo se iba sumando al malestar general de la población hacia el gobierno de la época (Bidstrup, 2001).

En 1964, la Feria Mundial de Nueva York condujo al alcalde de la ciudad, Robert Wagner, en medio de su preocupación por la imagen de su pueblo, a que declarará una intención directa para cerrar los locales homosexuales y detener cualquier actividad que pudiera considerarse inmoral o contranatural. Así, se extendió una red de policías encubiertos para identificar y arrestar a toda persona que se presumiera homosexual o que estuviera en contra de la ley de prohibición del alcohol, lo cual gestó un ambiente de miedo e incertidumbre entre la población (Wolf, 2009).

Las redadas policíacas no eran extrañas en Greenwich Village, estas solían ser cada mes y durante las cuales los consumidores de alcohol eran sacados a la calle, se interrogaba sobre su edad y se revisaba su identidad, se decomisaba el alcohol y cualquier sustancia prohibida. De manera concreta, se encontraba el bar Stonewall Inn, el cual fue fundado en 1966 y estaba dirigido, principalmente, a personas transexuales, travestis y transgénero de la ciudad de Nueva York, sin importar si estos eran blancos, negros o hispanos (Armstrong y Crage, 2006). La última semana de junio de 1969 las redadas habían clausurado varios clubs de las zonas aledañas al Stonewall Inn, por lo que la actividad policíaca estaba muy activa y fuertemente enfocada en este bar y sus clientes (Katz, 1976).

En la madrugada del sábado 28 de junio de 1969, la policía se presentó en Stonewall Inn para llevar a cabo una de las habituales redadas, sin embargo, a diferencia de otras ocasiones, esta vez los clientes se negaron al sometimiento y acoso policial. Esto generó que los agentes quisieran emprender un arresto colectivo, lo que elevó la incomodidad tanto de la policía como de los ahí presentes. Aunque todos fueron sacados del bar, los clientes no se retiraron del lugar y poco a poco fueron congregando a más personas afuera del establecimiento (Armstrong y Crage, 2006). Bastó un empujón y una respuesta para que se detonara una lluvia de piedras, botellas y monedas en contra de la policía, como también de fuertes agresiones de ellos hacia las personas de 
dentro y fuera del bar. Así, inició el disturbio, sin organización previa, pero con una causa gestada durante una década de acoso y represión policíaca (D'Emilio, 2012).

Esa madrugada de sábado fue de lucha, persecuciones y arrestos de parte de la policía. Dichos acontecimientos terminaron con la destrucción del Stonewall Inn y de amplias coberturas periodísticas de The New York Times, The New York Post y The New York Daily News (Katz, 1976). La noche de ese mismo sábado, grupos de personas transexuales y personas travestis se reunieron frente al local destruido para manifestar su enojo hacia lo sucedido y para declarar su derecho a mostrar su afecto de forma pública. Marsha P. Johnson, mujer negra trans, y Silvia Rivera, mujer latina trans, fueron dos figuras que no temieron al hecho de expresar su inconformidad con lo sucedido al reunir a miles de personas en esta nueva manifestación contra el acoso policial (Domínguez, 2019).

Aunque en los siguientes días los disturbios cesaron, estos marcaron un punto de inflexión en cuanto a que las cosas no podían seguir así. Días después, el 4 de julio, Mattachine Society se manifestó en Filadelfia con expresiones de afecto en público, lo cual no se había hecho anteriormente. En los meses siguientes, el Frente de Liberación Gay se fortaleció y se fundó la Alianza de Activismo Gay (Bullough, 2019). Cabe señalar que el término gay no se había utilizado hasta el momento y que aún los medios de comunicación se negaban a utilizarlo. Tanto el Frente como la Alianza se concentraron por completo en asuntos que aquejaban a los gays y se constituyeron con un solo objetivo: exigir la libertad de expresión y el respeto a la dignidad y el valor como seres humanos de los homosexuales (Katz, 1976).

De esta manera, las redadas no se detuvieron como tampoco las manifestaciones en contra de la policía, por su parte, los alcaldes de diversas ciudades provocaron que todo el año estuviera marcado por constantes disturbios y presiones de ambos bandos. En el primer aniversario de los disturbios de Stonewall Inn, se organizó la primera marcha del orgullo gay de la historia, en la que abiertamente se expresó la necesidad de cambiar (D'Emilio, 2012) . Esta marcha ocurriría solo en Nueva York, Los Ángeles y Chicago, aunque en 1971 se extendería a Boston, Dallas, París, Londres, Berlín y Estocolmo. De esta manera, lo que inició como un disturbio se convirtió en el movimiento de liberación gay, cuyas marchas se constituyeron en un hito que fragmentaría el metarrelato de lo socialmente aceptado (Corrales, 2017).

\subsection{EL MOVIMIENTO}

A dos años de los sucesos de Stonewall Inn, los grupos relacionados con la reivindicación de los derechos de las personas homosexuales y trans se expandieron a la mayor parte de las ciudades relevantes de los Estados Unidos, así como por Canadá, Europa Occidental y algunos países de Latinoamérica, bajo una premisa de cuatro elementos primordiales (Vázquez, Coss, León y Salinas, 2018):

a. La exposición de la discriminación, la represión estatal que venía dándose hacia la comunidad y la demanda de respeto e igualdad.

b. La visibilización de la población homosexual y la exigencia de un goce igualitario de derechos.

c. La generación de un referente para la organización de la lucha en otras regiones del mundo y la participación social y política de los homosexuales en sus comunidades y Gobiernos.

d. El desarrollo de una identidad cultural de la diversidad sexual.

No pasó mucho tiempo para que se comenzaran a ver resultados y logros. De hecho, en Estados Unidos, se destipificó la homosexualidad como enfermedad mental del Manual Diagnóstico y Estadístico de los Trastornos Mentales de la APA en 1973. Otro de los logros fue la incursión política de Harvey Milk como primer consejero abiertamente homosexual en un cargo público en San Francisco (López, 2018). En 1977, el movimiento llevó a cabo una lucha política contra la campaña conservadora Save our Children que buscaba revocar derechos civiles a los homosexuales en Florida y California. En 1978, se funda la Asociación Internacional de Lesbianas, Gays, Bisexuales, Trans e Intersexuales (ILGA), una red que aglutinaba a los diferentes grupos, instituciones y organizaciones bajo un frente común, cuyo objetivo consistía en luchar por 
la igualdad de lesbianas, gays, bisexuales y transexuales (LGBT). Incluso, actualmente, es la red más grande de organizaciones y colectivos en el mundo, lo que le ha permitido posicionar la agenda LGBTIQ+ en el ámbito internacional (Negroni, 2004).

En Alemania Occidental, se habla de que el movimiento de liberación gay alemán surge en 1971 con el estreno de la película No es perverso el homosexual, sino la situación en la que vive. Conforme se estrenaba la película en todo el país, se fueron generando nuevas organizaciones hasta llegar a fundar la Comunidad de Acción Homosexual Alemana en 1972, que organizaría la primera marcha del orgullo gay (Whisnant, 2012). El objetivo primordial de la lucha era abolir el artículo 175 que tipificaba las prácticas homosexuales como un crimen, al igual que también se abordaba la discriminación laboral. El punto central del movimiento alemán se daría en 1979 en la reunión de Homolulu, en Fráncfort, en dicho encuentro se reunieron personas homosexuales de toda Alemania para expresarse y dialogar sobre temas comunes que eran determinantes para todo el grupo. Para la década de los ochenta, diferentes colectivos comenzaron a incursionar en cuestiones políticas, por lo que ampliaron su ámbito de discusión y acción (Ayoub y Paternotte, 2014).

En Francia, los llamados Grupos de Liberación Homosexual fundados en 1974 se esparcieron rápidamente por todo el país, los cuales buscaban abrir espacios de diálogo sobre temas que a los homosexuales franceses les interesaban. El Comité de Urgencia Antirrepresión Homosexual, fundado en 1979, se enfocó principalmente en conseguir reformar el código penal y sus disposiciones discriminatorias, así como la organización de una marcha nacional en 1981 que reunió a más de diez mil participantes en París. Las reformas legales se dieron un año después (Merrick y Sibalis, 2013).

En España, según Martínez (2017), la lucha por el respeto y la igualdad se enfrentó a un apoyo mayoritario por la eliminación de la homosexualidad a través de legislaciones represivas durante la década de los setenta, época franquista. En 1975, se fundó el Movimiento Español de Liberación Homosexual que abrió camino para la creación de otras asociaciones similares en el país. En 1977, se convocó a la primera manifestación del orgullo LGBTIQ+ en Barcelona, pero dicha movilización fue fuertemente reprimida. Fue hasta 1979 que, bajo el gobierno de Adolfo Suárez, se modificó la ley de peligrosidad social que descartó a la homosexualidad como delito y la despenalizó en el Estado español.

En cuanto a Latinoamérica, se puede mencionar el caso de los movimientos activistas en México, Chile y Argentina, los cuales fueron igualmente significativos que los que se dieron en los Estados Unidos y Europa, aunque con un tinte mayormente enfocado en temas políticos. Es interesante señalar que, a diferencia de los países anglosajones, en Latinoamérica no se habla del movimiento de liberación gay, sino del movimiento de liberación homosexual, pues buscaba separar la lucha de la influencia capitalista que se venía dando en los Estados Unidos.

De forma concreta, se debe mencionar que en Chile y en Argentina, los procesos de desarrollo del activismo LGBTIQ+ se vieron ensombrecidos por las dictaduras militares de ambos países, lo cual, aunque no extinguió la lucha, sí la enlenteció. En Chile, tras el golpe militar que caracterizaría los años setenta y la fuerte represión social que significaría esto, el activismo se desarrolló de forma ilegal y clandestina. En 1977, se fundó el Grupo Integración, y en 1983, el Ayuquélen, que fue el primer grupo lésbico nacional (Levy, 2020). Algo interesante de señalar es que, con la caída de la dictadura militar, la disminución de la represión llevó a una proliferación considerable de establecimientos para homosexuales y una fuerte apertura de los movimientos, aunque fue hasta la década de los noventa que inició el movimiento de liberación chileno (Bidstrup, 2001).

De forma semejante, en Argentina, las primeras organizaciones de derechos LGBTIQ+ se fundaron en la segunda mitad de la década de los sesenta con organizaciones como Nuestro Mundo y Safo que luchaban por los derechos civiles de los homosexuales argentinos (Levy, 2020). Durante los setenta, el activismo homosexual se apegó al movimiento peronista de izquierda. Esto, si bien le dio cierto impulso a la lucha en un inicio, despertó fuertes rechazos de los partidarios de este movimiento político, lo que detonó, en consecuencia, una marcada represión hacia los homosexuales durante el Proceso de Reorganización Nacional. Durante la dictadura militar y hasta la década de los ochenta, miles de personas homosexuales fueron 
perseguidas, desaparecidas y asesinadas. En 1984, se fundó la Comunidad Homosexual Argentina, con la cual se reactiva el activismo en este país del sur; en 1992, se organiza la primera marcha del orgullo LGBTIQ+. Estos hechos demuestran que la lucha por los derechos de la comunidad LGBTIQ+ avanzaron lentamente a causa de la dictadura (Valdés, 1981).

De forma un tanto contrastante en México, los primeros grupos LGBTIQ+ se formaron en la década de los setenta, por ejemplo, el Frente de Liberación Homosexual o el Frente Homosexual de Acción Revolucionaria. Ambos solían relacionarse con movimientos políticos de izquierda (Weis, 2014). Durante esa década, el activismo homosexual mexicano fue muy significativo, lo que quedó en manifiesto con la primera marcha del orgullo en 1979, en la cual se exigía la libertad de expresión sexual y el respeto social y policial (Negroni, 2004).

Retomando las acciones del activismo de la tercera ola, es posible afirmar que esta trascendió el contexto local rápidamente y concentró su lucha en la despenalización de la homosexualidad, en la visibilidad individual y colectiva de la población diversa, en el rechazo a la represión estatal y social hacia la homosexualidad, en la educación sociosexual y la lucha contra el VIH.

\section{Nuevos REtos}

El primer reto al que se enfrentó el movimiento y activismo LGBTIQ+ en Occidente fue la crisis sanitaria del VIH de la década de los ochenta. Inicialmente, este virus se relacionó directamente con la comunidad homosexual, puesto que este era el grupo poblacional más afectado. La correspondencia entre la enfermedad y la comunidad gay fue tal que por varios años se le denominó la peste rosa (Linde, 2018). En 1983, se le nombra Virus de Inmunodeficiencia Humana (VIH), el cual desarrollaba la enfermedad llamada Síndrome de Inmunodeficiencia Adquirida (sida). Las organizaciones trabajaron mucho para romper con los estigmas establecidos hacia la comunidad producto de la enfermedad. En ese sentido, combatieron la desinformación para no afectar la lucha por la igualdad de derechos de las personas homosexuales (Coordinadora de Asociaciones de VIH y sida de la Comunidad Valenciana [Calcsicova], 2021).

En la década de los noventa, las movilizaciones se enfocaron en establecer un discurso de igualdad y no discriminación en todos los países de Occidente. Se consolidó el movimiento LGBTIQ+ y trabajaron con otras temáticas de relevancia para la comunidad, por ejemplo, la inclusión dentro de ambientes laborales y dentro de los espacios públicos, el matrimonio igualitario y la adopción homoparental, la incursión política, la abolición de las terapias de conversión y el desarrollo de una mayor apertura a otros grupos minoritarios del mismo colectivo, como las comunidades de personas transexuales, transgénero e intersexuales, las cuales habían sido poco consideradas por la lucha en las últimas décadas (Ball, 2019).

\subsection{LA OLA DE LA INTERSECCIONALIDAD}

La tercera ola no solo es una etapa en la que los grupos homosexuales buscan la igualdad de derechos. Este periodo también se enmarca como un momento histórico en el que es necesario reformular la lucha desde una visión de interseccionalidad, en la que se incluya a todas las personas que forman parte de esta comunidad de diversidad sexual y que habían sido excluidas en el pasado. Se podría clasificar esta situación como una cuarta ola, sin embargo, al considerar que la liberación gay todavía se encuentra en apogeo y que no ha tenido un desarrollo equilibrado y equitativo en todos los países, establecer esta división sería injusto para las regiones en las que aún se sigue luchando por la igualdad de condiciones de sus comunidades. Además, es preciso señalar que todavía hay muchos países en donde no se han abolido las leyes que segregan a las personas homosexuales. Aunado a ello, el hecho de pertenecer a estos grupos de diversidad se sanciona con penas corporales o, incluso, la muerte. En este sentido, más que señalar una cuarta ola, se opta por la adopción de una visión interseccional, la cual es en sí una segunda etapa de la tercera ola. 
Entre algunos momentos históricos claves para el tema de la interseccionalidad, se deben señalar los conflictos que se presentaron en 1973 entre el activismo lesbiano y las mujeres trans. Jean O'Leary, una activista feminista, excluía a los travestis de la lucha, porque consideraba que las mujeres travestis eran una burla a lo que significaba verdaderamente ser mujer. Este parecer no fue bien recibido por Sylvia Rivera y marcó una pauta para que se generaran varios disgustos entre los grupos. Al final Sylvia Rivera decidió abandonar el activismo gay para trabajar en temas concretos de la comunidad transgénero y travesti (Retzloff, 2007).

Aunque se podría pensar que tanto el feminismo como el movimiento de liberación gay transitaban un mismo camino -la búsqueda de la igualdad-, hubo varios conflictos entre el activismo de los diferentes grupos. El auge del lesbofeminismo en los años setenta provocó fuertes conflictos con el movimiento, pues consideraban que este tenía una clara tendencia machista y que atendía primordialmente las causas de los hombres gays (Hernández, 2017). En 1971, en Francia, un grupo de lesbianas feministas, liderado por Monique Wittig, acusaba que el Frente Homosexual de Acción Revolucionaria poseía demasiados componentes masculinos, lo que causaba tensiones y diferencias de opinión con relación a los objetivos que defendían las mujeres. Finalmente, Wittig y su grupo se separaron del frente y crearon su propio grupo: Movimiento de Liberación de las Mujeres. En 1977, se organizó una marcha del orgullo lésbico liderada por Adrienne Rich, quien consideraba que, como mujeres, no se compartían los temas de los hombres gays (Auchmuty, Jeffreys y Miller, 1992).

Asimismo, inició un rechazo hacia ciertos grupos de mujeres lesbianas con rasgos masculinos, pues los grupos feministas estimaban que esto era un juego de rol patriarcal y de dominación masculina, en el cual las mujeres desarrollaban papeles impuestos por la sociedad (Hernández, 2017). De igual forma, se rechazaba a los hombres gays amanerados, a los bisexuales y a todo el grupo trans, ya que se pensaba que representaban una subcultura que no era mayoritaria en el colectivo. En 1994, Sylvia Rivera lideró una marcha alternativa a la conmemoración de los 25 años de Stonewall Inn como una protesta por la exclusión de las personas transgénero en este evento (Jeffreys, 1997). Sin embargo, con el paso del tiempo el activismo LGBTIQ+ ha buscado retomar sus pasos y resarcir la exclusión, así como las diferencias que surgieron en las primeras etapas del movimiento por medio de una visión interseccional de la lucha.

El concepto de interseccionalidad fue introducido por Kimberlé Crenshaw en 2001 durante la Conferencia Mundial contra el Racismo en Sudáfrica. Desde su conceptualización, planteaba que tanto la raza como el género se vivían de maneras distintas y, además, conllevaban diversos efectos dentro de las personas. Para Crenshaw, las mujeres y los hombres vivían la discriminación de manera diferente, pero esta, a su vez, podría variar dependiendo si las personas son negras o blancas, o de condiciones sociales adineradas o pobres. La interseccionalidad muestra que la realidad se percibe de manera diferente, según la situación personal y de grupo que se experimente, lo que patentiza la existencia de estructuras de poder dentro de la sociedad contemporánea (Collins y Bilge, 2020).

Aunque la interseccionalidad se ha desarrollado ampliamente desde la teoría feminista, este es un concepto fácilmente aplicable a otros grupos, por ejemplo, la comunidad de la diversidad sexual. Desde esta perspectiva, se debe entender que la vivencia de la desigualdad y la discriminación han sido percibidas de formas distintas entre las personas que la integran (Collins, 2019). Así, aunque el movimiento de liberación gay pretendía velar por los derechos de todas las personas dentro de la agrupación, existían necesidades particulares que debieron ser consideradas de forma concreta por algunas partes del grupo, como resultaron ser las mujeres lesbianas o las mujeres trans (Rudy, 2001). Esta visión interseccional fue la que permitió que se gestaran nuevos movimientos -como el ya mencionado lesbofeminismo y el transfeminismo- sin que por ello fueran contrarios al gran paraguas de la lucha LGBTIQ+. Según Judith Butler (2015), el movimiento, aunque en sus inicios planteó la necesidad de generar una identidad cultural gay, no debe coartar, en ningún momento, el constante cambio de la noción de ser homosexual. Así, se han desarrollado experiencias diversas según el sexo, el género, la raza, la condición social, entre otros aspectos. 
De esta forma, esta tercera ola implica la necesidad de una apertura, así como de un replanteamiento de los objetivos del movimiento, incluyendo a todos aquellos que valoren que su experiencia debería ser considerada. Como resultado de lo anterior, el acrónimo inicial de LGBTIQ+ ha tenido que ampliarse con el paso del tiempo, puesto que se han incluido otros subconjuntos del colectivo que no estaban siendo visibilizados, tales como travestis, transexuales, transgénero, intersexuales, queer y asexuales (LGBTTTIQA). Como ilustración de lo anterior, a mediados de la década de los noventa, se incluyó a los bisexuales dentro de la causa y, en el aniversario cincuenta de los disturbios en Stonewall Inn en 2019, se reconoció públicamente la importancia de Marsha P. Johnson y Sylvia Rivera como iniciadoras del movimiento, para quienes se construyó un monumento en la ciudad de Nueva York.

\section{CONCLUSIONES}

El presente artículo supone un aporte dentro de los estudios LGBTIQ+ porque plantea una posible clasificación historiográfica del desarrollo de los movimientos de activismo en Occidente, lo cual no se ha hecho de manera pormenorizada. Además, se plantea la posibilidad de que se generen nuevos estudios, así como análisis sobre las implicaciones materiales e inmateriales en cada una de estas etapas.

Aunque se reconoce que el texto se plantea desde un abordaje que pudiera ser sesgado, por no incluir una mayor amplitud territorial o regional, se estima que se abordan los momentos más relevantes del movimiento en Occidente. Se considera que estos fueron determinantes aunque, posteriormente, se repitieran de forma local con características propias de cada región. De igual forma, se reflexionó desde la visión general del movimiento y, aunque en el último apartado se intentó ampliar el panorama hacia algunos de los otros grupos particulares, se reconoce que hay mucho por investigar y comunicar con relación a estas temáticas, tal como el movimiento lesbiano y trans.

A pesar de estas limitaciones, esta clasificación posee relevancia porque ubica a esta colectividad dentro de la historia del activismo social. En este sentido, las olas o etapas propuestas permiten dar un paso adicional dentro de la explicación, la argumentación y la construcción de reflexiones académicas en torno a la lucha de este grupo.

Hay que destacar la relevancia de que todas las personas conozcan el pasado, así como los movimientos sociales que les han permitido disfrutar de sus derechos. Reconocer el valor y el sacrificio de ello es una obligación. Finalmente, el movimiento LGBTIQ+ no solo se debe a hombres homosexuales blancos, sino también a mujeres negras, latinas, lesbianas y transexuales, quienes sin ser intelectuales, políticas o de clase alta decidieron levantar su voz, reclamar sus derechos, consignar las demandas de muchos y vivir en su carne el sacrificio de todos.

\section{REFERENCIAS BibLIOGRÁFICAS}

Aries, P. (1987). Reflexiones en torno a la historia de la homosexualidad. Paidos.

Armstrong, E. y Crage, S. (2006). Movements and Memory: The Making of the Stonewall Myth. American Sociological Review, 71(5), 724-751.

Auchmuty, R., Jeffreys, S. y Miller, E. (1992). Lesbian History and Gay Studies: Keeping a Feminist Perspective. Women's History Review, 1(1), 89-108.

Ayoub, P. y Paternotte, D. (2014). LGBT Activism and the Making of Europe: A Rainbow Europe? Springer.

Baker, C. (2016). Transnational 'LGBT' Politics after the Cold War and Implications for Gender History. Palgrave Macmillan.

Ball, C. (2019). After Marriage Equality: The future of LGBT Rights. NYU Press. 
Bidstrup, S. (2001). Homosexualidad en la historia. SIGLA Sociedad de Integración Gay Lésbica Argentina. http://www.sigla.org.ar/index.php?option=com_content\&view=article\&id=91:homosexualidad-e n-la-historia-parte-1\&Itemid $=104$

Buckle, S. (2015). The Way Out: A History of Homosexuality in Modern Britain. Bloomsbury Publishing.

Bullough, V. (2019). Homosexuality: A History (From Ancient Greece to Gay Liberation). Routledge.

Butler, J. (2015). El género en disputa. Paidós.

Collins, P. (2019). Intersectionality as Critical Social Theory. Duke University Press.

Collins, P. y Bilge, S. (2020). Intersectionality. John Wiley \& Sons.

Coordinadora de Asociaciones de VIH y sida de la Comunidad Valenciana. (2021). Info VIH i SIDA. https://www .calcsicova.org/vih-i-sida/

Corrales, J. (2017). Undertanding the Uneven Spread of LGBT Rights in Latin America and the Caribbean. Journal of Research in Gender Studies, 7(1), 52-82.

D'Emilio, J. (2012). Prefacio. En St. Sukie de la Croix, Chicago Whispers: A History of LGBT Chicago before Stonewall (pp. IX-XVI). University of Wisconsin Pres.

Domínguez, V. (2019). Ser LGBTI. Programa de las Naciones Unidas para el Desarrollo. https://www.undp.org/co ntent/undp/es/home/blog/2019/being-lgbti.html

Dynes, W. y Donaldson, S. (1992a). Asian Homosexuality (Vol. 3). Taylor \& Francis.

Dynes, W. y Donaldson, S. (1992b). History of Homosexuality in Europe and America (Vol. 5). Taylor \& Francis.

Geoghegan, T. (2019). Stonewall, la histórica noche en que los gays se rebelaron en un bar de Nueva York y cambiaron millones de vidas. BBC News, Washington. https://www.bbc.com/mundo/noticias-internacional-48718688

Griffin, S. (2006). Queer Images: A History of Gay and Lesbian Film in America.Rowman \& Littlefield Pub.

Halperin, D. (1990). One Hundred Years of Homosexuality: And Other Essays on Greek Love. Psychology Press.

Hekma, G. (1989). A History of Sexology. From Sappho to De Sade: Moments in the History of Sexuality. Routledge.

Hernández, I. (2017). Colonialidad feminista, sociosexual y aportes lesbofeministas antirracistas descoloniales. Nomadias, (24), 67-87.

Jeffreys, S. (1997). Transgender Activism: A Lesbian Feminist Perspective. Journal of lesbian studies, 1(3), 55-74.

Jowett, A. (2017). Representing the History of LGBT Rights: Political Rhetoric Surrounding the 50th Anniversary of the Sexual Offences Act 1967. Psychology \& Sexuality, 8(4), 306-317.

Katz, J. (1976). Gay American History: Lesbians and Gay Men in the USA: A Documentary. Crowell.

Levy, M. (2020). Gay Rights Movement. Britannica. https://www.britannica.com/topic/gay-rights-movement

Linde, P. (2018, 19 de mayo). 35 años del descubrimiento de aquel extraño y mortal virus. El País. https://elpais.com/ elpais/2018/05/16/planeta_futuro/1526425640_348314.html

Logan, L. (2013). Status Homophily, Sexual Identity, and Lesbian Social Ties. Journal of Homosexuality, 60(10), 1494-1519.

López, J. (2018). Movilización y contramovilización frente a los derechos LGBTI. Respuestas conservadoras al reconocimiento de los derechos humanos. Estudios sociológicos, 36(106), 161-187.

Martínez, R. (2017). Lo nuestro sí que es mundial. Una introducción a la historia del movimiento LGTB en España. Egales.

Merrick, J. y Sibalis, M. (2013). Homosexuality in French History and Culture. Routledge.

Negroni, M. (2004). From Movement Demands to Legislation: Organizing in the LGBT Community in Mexico City. Journal of Gay \& Lesbian Social Services, 16(3-4), 207-218.

Nicholson, L. (2010). Feminism in 'Waves': Useful Metaphor or Not? New Politics, 12(4), 34-39.

Rayor, D. (2003). Homosexuality in Greece and Rome: A Sourcebook of Basic Documents. Univ of California Press.

Retzloff, T. (2007). Eliding trans Latino/a Queer Experience in US LGBT History: José Sarria and Sylvia Rivera Reexamined. Centro Journal, 19(1), 140-161. 
Dr. José Carlos Vázquez Parra. Las olas del movimiento LGBTiQ+. Una propuesta desde la historiogra...

Rudy, K. (2001). Radical Feminism, Lesbian Separatism, and Queer Theory. Feminist Studies, 27(1), 191-222.

Rydström, J. y Mustola, K. (2007). Criminally Queer: Homosexuality and Criminal Law in Scandinavia 1842-1999. Aksant Academic Publishers.

Suárez, D. (2019, 28 de febrero). El mar proceloso del feminismo: ¿en qué ola estamos? Economía Femini(s)ta. https:/ /economiafeminita.com/en-que-ola-estamos/

Tamagne, F. (2006). A History of Homosexuality in Europe. Algora Publishing.

Valdés, A. (1981). Historia y presente de la homosexualidad. Ediciones Akal.

Vanita, R. (2002). Homosexuality in India: Past and Present. Global Humanities and Religions Faculty Publications, 29(5), 10-11. https://scholarworks.umt.edu/libstudies_pubs/5

Vázquez, J., Coss y León, D. y Salinas, O. (2018). Una aproximación histórico-social a la evolución de los derechos de la comunidad LGBTI+ en México. Humanidades, 9(2), 13-26.

Weis, R. (2014, 27 de octubre). El activismo LGBT en México: nuevos retos... viejas amenazas. HEINRICH BÖLL STIFTUNG. https://mx.boell.org/es/2014/10/27/el-activismo-lgbt-en-mexico-nuevos-retos-viejas-amenazas

Whisnant, C. (2012). Male homosexuality in West Germany: Between Persecution and Freedom, 1945-1969. Springer.

Wolf, S. (2009). Sexuality and Socialism: History, Politics and Theory of LGBT Liberation. Haymarket Books. 